Article

\title{
The Climatological Analysis of Typhoon Tracks, Steering Flow, and the Pacific Subtropical High in the Vicinity of Taiwan and the Western North Pacific
}

\author{
Chih-wen Hung *, Ming-Fu Shih and Te-Yuan Lin \\ Department of Geography, National Taiwan Normal University, Taipei 106, Taiwan; \\ shihmingfu777@gmail.com (M.-F.S.); linteyuan@gmail.com (T.-Y.L.) \\ * Correspondence: hungchihwen@gmail.com
}

Received: 7 April 2020; Accepted: 20 May 2020; Published: 23 May 2020

check for updates

\begin{abstract}
Taiwan frequently suffers from typhoon hits in the boreal summer and fall. The location of Taiwan makes it vulnerable to the pathways of typhoons mainly determined by the position of the Pacific subtropical high. In order to clarify the linkage between typhoon invasion and associated large-scale environments from a climatological perspective, this study counts the historical typhoon invasion days for each month in the typhoon season to establish analyzed cases and then categorizes them with statistical thresholds. Besides, the categorized cases with less typhoon invasion are further sorted to distinguish different movements of tropical cyclones. Therefore, corresponding composites are applied for each category. The results reveal that when the subtropical high retreats eastward, the accompanying steering flow guides typhoons to make an early recurvature toward Japan and South Korea. While the subtropical high further extends its property to the west covering Taiwan, the steering flow on the south transfers typhoons moving westward to the South China Sea. However, when the subtropical high lies in areas between the above two scenarios, the steering flow along the periphery of the subtropical high continuously sends typhoons toward Taiwan and the vicinity, which greatly increases the threat to the island.
\end{abstract}

Keywords: typhoon track; steering flow; pacific subtropical high; typhoon path

\section{Introduction}

The Western North Pacific features the most frequent tropical cyclone (typhoon) activity in the world. According to statistics from 1961 to 1990, the average annual number of typhoons over that region $\left(100^{\circ} \mathrm{E}\right.$ to $180^{\circ} \mathrm{E}$ in the Northern Hemisphere) is 27.8 , accounting for about one-third of global tropical cyclone genesis [1]. Because Taiwan is located in Southeast Asia, the island is frequently hit by typhoons in the boreal summer and fall, resulting in catastrophic disasters. The violent wind speed and torrential precipitation from typhoons have often caused extensive damage throughout history. For example, in 2001, typhoon Nari brought severe flooding and sorely damaged the transportation system in northern Taiwan; typhoon Morakot, which caused the well-known destructive flood in 2009, killed 681 people.

Taiwan usually suffers three to four typhoon hits annually on average, meaning the island is constantly exposed to the risk of extreme rainfall and flooding. That fact prompted the scientific community to study typhoon-related topics. Chien and Kuo (2011) [2] explored the factors that contributed to typhoon Morakot's record-breaking precipitation over southern Taiwan, and stated the amount of rainfall in Taiwan was nearly proportional to the reciprocal of the tropical cyclone translation speed. Huang et al. (2016) [3] analyzed convective systems of typhoon Fanapi, which brought considerable precipitation to the southern Taiwan plain and the central range. They argued that the 
positive potential vorticity tendency near the coast was induced by both vertical and longitudinal differential diabatic heating. Su et al. (2012) [4] indicated that monsoon water supply, a typhoon's slow translation speed, and mesoscale convection due to typhoon-monsoon flow interactions are critical factors in torrential precipitation.

Although typhoons often lead to enormous economic losses and casualties, the intense precipitation is also an indispensable water resource for Taiwan. Kubota and Wang (2009) [5] examined weather station data within an area of $7^{\circ} \mathrm{N}$ to $13^{\circ} \mathrm{N}$, and $120^{\circ} \mathrm{E}$ to $130^{\circ} \mathrm{E}$, pointing out that the precipitation from typhoons accounts for around 50\% to $60 \%$ of the total rainfall in East Asia during the period of July to October, and that proportion number would rise to $60 \%$ in Hualien, Taiwan. Hung and Hsu (2010) [6] analyzed data from 1958 to 2001, and the statistics showed that typhoons contributed $43.2 \%$ of the total rainfall in Taiwan from July to October. However, the typhoon-related water precipitated onto the island was provided by only 14 typhoon days on average, which firmly indicated that the torrential precipitation was brought from the typhoons. Additionally, if the southwesterly flows associated with the typhoons were taken into account, the extra two rainy days from the flows after the typhoons would largely raise that proportion number to $53.2 \%$. A similar result was obtained by Chen et al. 2010 [7]. According to their study, of the total precipitation from July to September during the period of 1950 to 2002 , about $47.5 \%$ of it came from typhoons, and monsoons filled up the rest of the number of about $52.5 \%$. Nearly half of the precipitation during summer and early fall in Taiwan was contributed by the typhoons, which constituted a principal water resource for Taiwan during a year.

If an ideal pattern for atmospheric circulation occurs in the typhoon season, typhoons would be frequently guided toward Taiwan. Hence, the number of typhoons invading Taiwan, the length of their influence time, and their associated precipitation are important topics for research. Considering the amount of precipitation brought from a typhoon is an intuitive way to reflect the activity of the typhoon; most of the previous studies started with a rainfall analysis to explore the typhoon-related impact mechanisms from the relevant atmospheric environment. Many studies have pointed out that the amount of precipitation is closely related to the degree of typhoon activity. In other words, if typhoons in the vicinity of Taiwan become more active than usual, they should bring more water to the island.

Chen et al. (2010) [7] argued that for those years when the precipitation from the typhoon is more than that from the monsoon, the related large-scale environment features a cyclonic anomaly lying southeast of Taiwan. In this case, Taiwan is located in an anomalous water vapor advection from the northeast with a weak vertical ascending motion; hence, the precipitation caused by the monsoon from the southwest is reduced. Meanwhile, a stronger positive vorticity and an ascending motion are found on the ocean southeast of Taiwan. Typhoons over that oceanic region are more likely to develop well and move closer to Taiwan, resulting in more typhoon precipitation. Chen and Chen (2011) [8] calculated typhoon and monsoon precipitation from June to August during the period of 1950 to 2008, and the results showed an increase for typhoons and a decrease for monsoons. Through the analysis of environmental fields, it showed that a cyclonic circulation anomaly lay over the subtropical Pacific Ocean during that period, which weakened the resident subtropical high and reduced vertical wind shear over the Philippine Sea. Together with the scenario mentioned above, warm sea surface temperature (SST) additionally favored the convective system for the typhoon to generate and develop, and sequentially moved toward Taiwan along the peripheral of the subtropical high. Chen and Fan (2003) [9] found that when the summer precipitation in the South China Sea is higher than usual, the composite results showed there is a cyclonic anomaly at $850 \mathrm{hPa}$ over the South China Sea, with an anticyclonic one seen over Japan. Since typhoons tend to move toward the cyclonic anomaly area, Taiwan is more likely to be impacted by the tropical cyclone.

In order to investigate typhoon activity around Taiwan, some previous studies took a different approach via looking into their associated large-scale environmental fields. Tu and Chen (2019) [10] analyzed typhoon activity around Taiwan in the boreal summer and early fall with their defined Western Pacific subtropical high and SST indices. During the typhoon-active summer, there are 
cold SST anomalies between the Bay of Bengal and the Philippine Sea, and warm SST anomalies in the tropical Western and Central Pacific. The SST gradient between each forms a convergence zone through the Walker circulation over the Western North Pacific, and Matsuno-Gill-type [11,12] circulation characteristics appear. It also exhibits Pacific-Japan (PJ) pattern [13] characteristics, so more typhoons approach Taiwan. As for the typhoon-active fall, warm (cold) SST anomalies are seen in the tropical Western (Eastern) Pacific with a convergence (divergence) pattern over the same region. In the meantime, a Matsuno-Gill-type circulation driven by the convergence center is also found, which brings a cyclonic circulation southwest of Taiwan and an anticyclonic circulation extending to the northwest over the Western North Pacific. In this situation, Taiwan and its vicinity are more prone to typhoon passage.

Based on the findings proposed by the research mentioned above, one should realize that the degree of typhoon activity in Taiwan is closely related to large-scale environmental fields in the Western North Pacific or neighboring areas of Taiwan. Because of the small geographical area of Taiwan, any slight difference in the spatial configuration of the large-scale environmental field would considerably change the extent of the typhoon impact. Therefore, the frequency of typhoon invasion varies largely from year to year.

Some researchers suggested that large-scale circulations would not only exert their influences on typhoon motion but also affect the length of the typhoon impact period. Chu et al. (2012) [14] indicated the weakening of the easterly steering flow would slow down the movement of a typhoon and thus extend the period of typhoon invasion. Tu and Chou (2013) [15] also argued that the slower movement of a typhoon caused by the weaker steering flow is a factor that enhances typhoon precipitation in Taiwan. Chang et al. (2013) [16] studied 84 typhoon cases that made landfall in Taiwan from 1960 to 2011 and counted rainfall data from 21 stations operated by the Central Weather Bureau (CWB). The results also showed an increase in typhoon precipitation for the island. They attributed the findings to the weakening of the easterly steering flow that extended the periods of the typhoon impacts. In addition, the southwesterly winds not only caused the typhoons to drop more rain after the tropical cyclones left from the west coast of the island, but also affected the large-scale environment again, which weakened the easterly steering flow to slow down the motions of the typhoons.

Previously, many researchers focused on case studies when it came to analyzing factors that influence typhoon motion. Huang et al. (2011) [17] used high-resolution simulations to examine the eminent deflection of typhoon Krosa's track before its landfall over a mountainous island topography. Yeh et al. (2012) [18] studied the looping motion of typhoon Haitang prior to making landfall in Taiwan and showed the importance of a terrain-induced vortex interacting with the typhoon. However, those studies were usually confined to the scope of the mesoscale. In order to take a look at typhoon motion from a broader viewpoint, this study tries a different concept via categorizing historical typhoons that invaded Taiwan from a climatological point of view. After that, our work examines different corresponding large-scale environmental conditions for the goal of clarifying what mechanisms affect the movement of a typhoon. In addition, rather than investigating some common objects, such as typhoon rainfall and typhoon amount, this study chooses to look at things from counting the historical typhoon invasion days in Taiwan.

The following Section 2 will introduce the data used in this study for the analysis. The statistical categorization method and related formula will be detailed in Section 3. The categorized results and the corresponding large-scale environmental fields in the Western North Pacific will be presented in Section 4 to understand the role of large-scale circulations in the entire scenario. Finally, the discussion and conclusions will be provided in Section 5, where we will discuss other major factors influencing typhoon activity and go over our results, subsequently highlighting the specialties of this study.

\section{Data}

This study uses multiple datasets to investigate typhoons and their associated large-scale environmental fields. The Joint Typhoon Warning Center (JTWC) data, which has been recording 
typhoon tracks and activities within the Western North Pacific at 6-hour intervals since 1945, is obtained for the investigation of typhoon tracks. In this study, "The Best Track" from the JTWC is used as the typhoon track data to statistically count and categorize the typhoon invasion day in Taiwan as well as providing the necessary information for the analysis of typhoon motion over the Western North Pacific. The time zone of the original data is converted to UTC +8 to fit the allocated zone for Taiwan. As for precipitation data, daily observed precipitation data from two CWB synoptic weather stations, Taipei and Tainan, representing the northern and southern Taiwan, respectively, and the Taiwan Rainfall Index (TRI) [19] are adopted to verify the precipitation characteristic for each analyzed case. The sources of the TRI include 22 synoptic weather stations and 253 automatic weather stations operated by the CWB and 901 Taiwan rainfall stations (1176 stations in total), with a time span of 119 years, from 1897 to 2015 . This study accesses the 1950 to 2014 segment.

In order to understand the relationship between the large-scale environmental fields over the Western North Pacific and the motion of the tropical cyclone, this study obtains the NOAA-CIRES Twentieth Century Reanalysis (V2c) dataset through the following website: https://www.esrl.noaa. gov/psd/ [20]. The time span of the monthly data is from 1851 to 2014; our analyzed period here takes the segment from 1950 to 2014 . The spatial grid resolution is $2^{\circ} \times 2^{\circ}$, covering the whole world, including several analyzed variables such as $u, v$ winds at each pressure level, sea level pressure (SLP), and $500 \mathrm{hPa}$ geopotential height.

\section{Methodology}

\subsection{Establishing the Typhoon (Ty) Category}

In order to select the case of typhoon invasion, determine the impact duration, and distinguish the typhoon-related precipitation, a straightforward method adopted by many studies is to identify the influence of the typhoon with a rectangular domain. In other words, when a typhoon center enters this rectangular domain, it is defined as a case of typhoon invasion. Tu et al. (2009) [21] analyzed typhoon tracks over the Western North Pacific and examined the change in typhoon activity near Taiwan by a domain ranging from $21^{\circ} \mathrm{N}$ to $26^{\circ} \mathrm{N}$ and from $119^{\circ} \mathrm{E}$ to $125^{\circ} \mathrm{E}$. Tu and Chou (2013) [15] indicated that most of the heavy rain $\left(30 \mathrm{~mm} \mathrm{~h}^{-1}\right.$ to $\left.50 \mathrm{~mm} \mathrm{~h}^{-1}\right)$ appears in a range of within $500 \mathrm{~km}$ from the center of a typhoon, and the highest frequency of the heavy rain occurs in the range of $100 \mathrm{~km}$ to $300 \mathrm{~km}$ from the center. Based on that, for their research, a rectangular domain from $18^{\circ} \mathrm{N}$ to $29.5^{\circ} \mathrm{N}$ and from $116^{\circ} \mathrm{E}$ to $126^{\circ} \mathrm{E}$ is regarded as the area where a typhoon affects Taiwan.

Considering the typhoon storm radius defined by the CWB is about $200 \mathrm{~km}$ to $300 \mathrm{~km}$, and the major storm radius of the typhoon mentioned in the studies above is within $300 \mathrm{~km}$ from the center outward, our work defines a rectangular domain centered over Taiwan. It expands the boundaries outside the island by an extra 3 degrees for both latitude and longitude. Finally, a domain ranging from $19^{\circ} \mathrm{N}$ to $28^{\circ} \mathrm{N}$ and from $117^{\circ} \mathrm{E}$ to $125^{\circ} \mathrm{E}$ is set to identify the typhoon invasion for the study.

Even though typhoons can be generated in any season over the Western North Pacific, Taiwan is mainly affected by tropical cyclones in the boreal summer and fall, with the highest probability of being invaded from July to September. According to the statistics from 1950 to 2014, the averaged typhoon invasion day in Taiwan for each month is 3.23 days in July, 4.2 days in August, and 4.48 days in September.

For each month from July to September over the investigated years from 1950 to 2014, when a typhoon's center falls into the above-defined domain, its impact day starts being counted until the center moves out of the domain. One should note that there are cases that the lifespan of a typhoon occurs during two continuous months. In that situation, its typhoon invasion days are separately counted and adjudicated for the corresponding month. Through this definition, 65 years $\times 3$ months, all 195 analyzed cases are individually assigned a number representing the typhoon invasion day.

Rather than treating the entire typhoon season as a whole, the method adopted in this study is to statistically set thresholds for each investigated month to categorize the cases established, which 
will ensure that the qualified cases are statistically representative. This method also avoids the contamination of statistical characteristics from other months while the thresholds for each month are defined.

In order to set thresholds and categorize all the analyzed cases by the typhoon invasion day, our work first calculates the standard deviation from all the analyzed cases for each month based on the typhoon invasion day, and the results show 2.42 days in July, 3.2 days in August, and 3.77 days in September. A threshold as the upper (lower) boundary is defined as the averaged typhoon invasion day plus (minus) 0.5 standard deviations. After all, this method yields two different thresholds for each month, namely 4.44 days and 2.02 days for July, 5.8 days and 2.6 days for August, and 6.37 days and 2.6 days for September.

Therefore, a case where the number of the typhoon invasion days is more than the upper threshold is defined as "more typhoon invasion days (hereafter Ty+)". Meanwhile, a case where the number of the typhoon invasion days is less than the lower threshold is defined as "less typhoon invasion days (hereafter Ty-)“. The remaining analyzed cases that do not exceed either the upper or lower thresholds stay closer to the mean state. Those cases are considered normal cases and excluded for further study. Since most of the typhoon movements in the Ty- category are found to separate in two different directions, a verification domain is delimited by high overall passing frequency areas in each direction. The way to determine the classification of the two paths from the Ty- category is to count the overall frequency within each verification domain and then select the one with more typhoon passages as the final decision based on its corresponding path. Therefore, the typhoons from the Ty- category are further subdivided into two additional subcategories: "Recurving path" and "Westbound path".

\subsection{Calculating Steering Flow}

In order to calculate averaged steering flow across multiple pressure layers, this study refers to the study of Kimberlain and Breman (2017) [22], who pointed out that the averaged wind across layers of the troposphere is highly correlated with the actual movement of tropical cyclones. The method to calculate this multi-layer averaged wind should adopt the concept of the mass-weighted average, as they suggested in their study.

The steering flow, which is usually adopted to analyze the typhoon movement, is based on an averaged wind field across $300 \mathrm{hPa}$ to $850 \mathrm{hPa}$ [23]. In this study, $u$ and $v$ wind data taken from the NOAA-CIRES Twentieth Century Reanalysis (V2c) are equally divided by $50 \mathrm{hPa}$, creating 11 intervals of layers between $300 \mathrm{hPa}$ and $850 \mathrm{hPa}$. Based on the mass-weighted average calculation method proposed by Kimberlain and Breman (2017) [22], this study reformulates the formula and takes the following case as an example: to calculate the averaged $u$ wind from $300 \mathrm{hPa}$ to $850 \mathrm{hPa}$, the formula should be

$$
\left[\left(U_{850}+U_{300}\right) / 2+\sum_{k=1}^{10} U_{(50 k+300)}\right] / 11 .
$$

The same formula can be applied to calculate the averaged $v$ wind by replacing $u$ components with $v$. After obtaining the averaged $u$ and $v$ wind fields across $300 \mathrm{hPa}$ to $850 \mathrm{hPa}$ through the above formula, the averaged steering flow and the averaged wind speed can be obtained.

\section{Results}

\subsection{The Ty Categories}

After establishing the Ty categories, the corresponding years of the categorized cases for each investigated month are listed in Table 1. Our definition avoids the contamination of statistical characteristics from a month with others because the averaged value and standard deviation are exclusively calculated from each investigated month to produce its thresholds. It allows the categorizing process to retain physical information from each analyzed case ideally, and thus secures representativeness for the categorized cases to best reflect the relevant large-scale environmental fields. 
In Figure 1, a category is given for each analyzed case with the corresponding year and month to schematically indicate the dominating category for that period.

Table 1. Year list for the Ty+ category and Ty- category in each investigated month.

\begin{tabular}{cccccc}
\hline & \multicolumn{2}{c}{ July } & \multicolumn{2}{c}{ August } & \multicolumn{2}{c}{ September } \\
\hline Ty+ & Ty- & Ty+ & Ty- & Ty+ & Ty- \\
\hline 1952 & 1950 & 1960 & 1950 & 1956 & 1950 \\
1961 & 1951 & 1961 & 1951 & 1957 & 1954 \\
1962 & 1953 & 1962 & 1952 & 1959 & 1955 \\
1966 & 1954 & 1972 & 1954 & 1963 & 1958 \\
1968 & 1955 & 1974 & 1956 & 1966 & 1960 \\
1972 & 1956 & 1982 & 1957 & 1974 & 1965 \\
1973 & 1957 & 1986 & 1958 & 1977 & 1967 \\
1977 & 1958 & 1990 & 1963 & 1989 & 1972 \\
1979 & 1959 & 1992 & 1964 & 1990 & 1975 \\
1987 & 1960 & 1994 & 1967 & 1991 & 1976 \\
1990 & 1970 & 1995 & 1969 & 1992 & 1979 \\
1998 & 1974 & 1997 & 1970 & 1993 & 1981 \\
2000 & 1975 & 2003 & 1971 & 2001 & 1984 \\
2001 & 1976 & 2004 & 1983 & 2008 & 1988 \\
2002 & 1978 & 2005 & 1987 & 2010 & 1996 \\
2004 & 1983 & 2007 & 1988 & - & 1997 \\
2006 & 1985 & 2008 & 2001 & - & 2003 \\
2008 & 1986 & 2010 & 2002 & - & 2007 \\
2013 & 1988 & 2012 & 2014 & - & 2009 \\
- & 1989 & 2013 & - & - & 2011 \\
- & 1992 & - & - & - & 2012 \\
- & 1993 & - & - & - & - \\
- & 1995 & - & - & - & - \\
- & 1997 & - & - & - & - \\
- & 1999 & - & - & - & - \\
- & 2003 & - & - & - & - \\
- & 2007 & - & - & - & - \\
- & 2010 & - & - & - & - \\
- & 2011 & - & - & - & - \\
\hline
\end{tabular}

For the following analyses, all the categorized cases from each investigated month will be gathered and discussed based on their corresponding category. The results will represent different typhoon-associated atmospheric conditions during the typhoon season from July to September. The relevant information of the Ty+ category, Ty- category, and normal cases are presented in Figure 2. Among the total 195 analyzed cases from July to September over the analyzed years, the Ty- category shows similarity to the normal cases in terms of the amount (Figure 2a), while the Ty+ category is considerably less than the others.

Figure $2 \mathrm{~b}$ shows the monthly typhoon invasion day for each category. The statistical results reveal that most typhoons invading Taiwan tend to stroll around the island or adjacent areas for a few days with an averaged typhoon invasion spell of about four days per month. Since the components from the normal cases do not show an obvious tendency toward any category, and do not pass the 0.5 standard deviations threshold, the number of days is very close to the climatology value as expected. Meanwhile, a massive difference in the monthly typhoon invasion days is seen between the Ty+ category and the Ty- category, with the number from the Ty+ category almost reaching eight times the number from the Ty- category, which also implies that the mechanisms affecting the two categories should be different. 


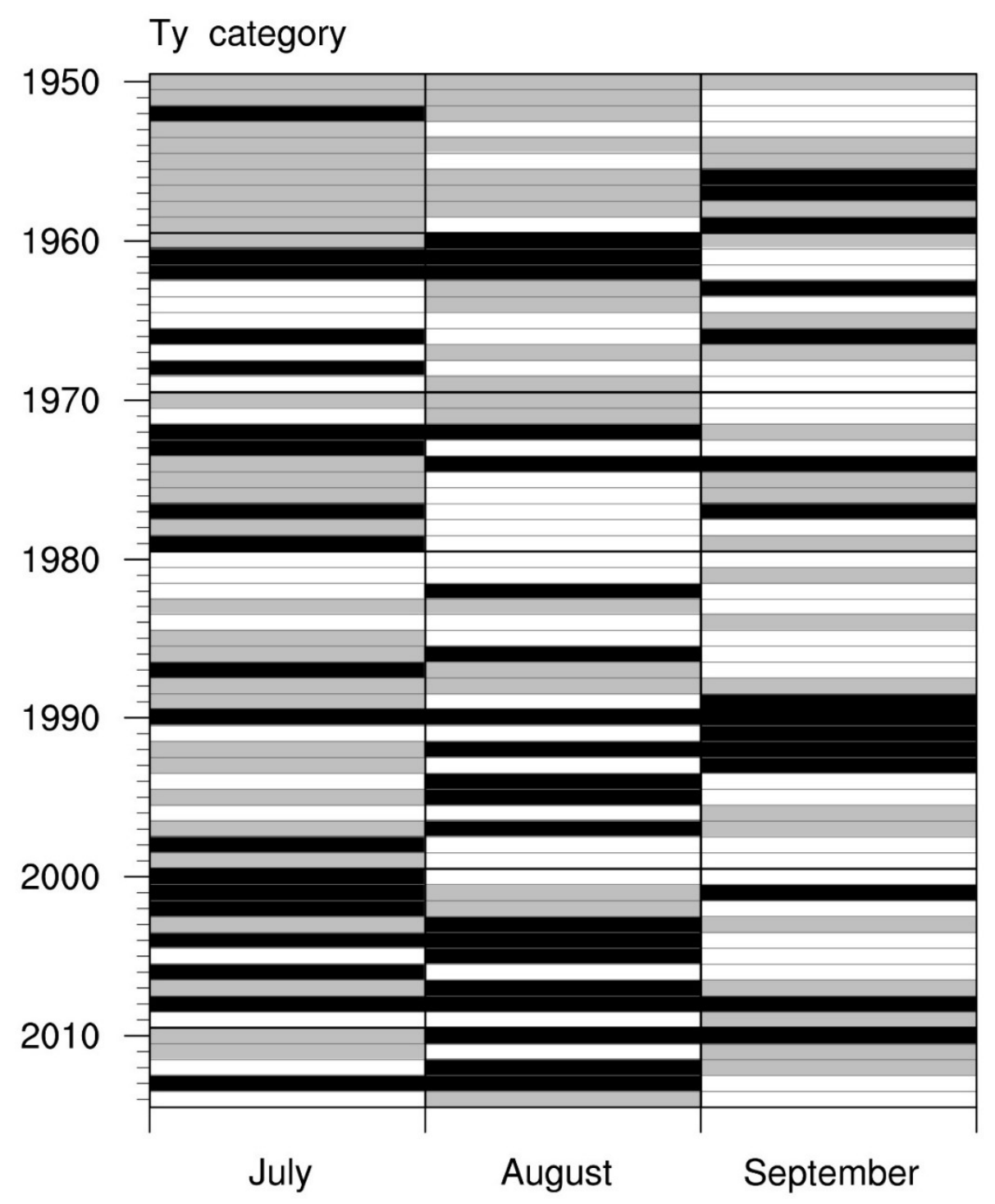

Figure 1. Different categories sorted by the typhoon invasion days for the typhoon season in Taiwan over the analyzed years. Black for the Ty+ category, gray for the Ty- category, and white for the normal cases.

Generally, typhoon-related rainfall should be proportional to the duration of the invasion. Figure $2 \mathrm{c}, \mathrm{d}$, respectively, present typhoon-related precipitation conditions by the observational rainfall averaged from the CWB Taipei and Tainan stations, and the TRI. Regarding the precipitation observed at the Taipei and Tainan stations (Figure 2c), the averaged value from the normal cases, again as expected, is similar to the climatology value, and the other two categories show clearly proportional results to the typhoon invasion day. In other words, when a typhoon affects an area for longer, the rainfall rises, and vice versa [24]. A similar situation is also reflected in the analysis of the TRI (Figure 2d). One should note that the Ty+ category contributes nearly half of the total precipitation from all the analyzed cases. Considering the rather small number of cases but torrential precipitation from this category, it is reasonable to imagine that Taiwan would suffer from severe disasters.

Since Taiwan is located in the Western North Pacific, which accounts for the most substantial portion of typhoon genesis globally, one should wonder about the linkage between the level of typhoon activity over that oceanic region and the extent of typhoon invasion in Taiwan. For that, this study also investigates the relationship between the number of typhoons invading Taiwan and the number of typhoons generated over the Western North Pacific based on our categories for each investigated month. 
(a) JAS analyzed case amount

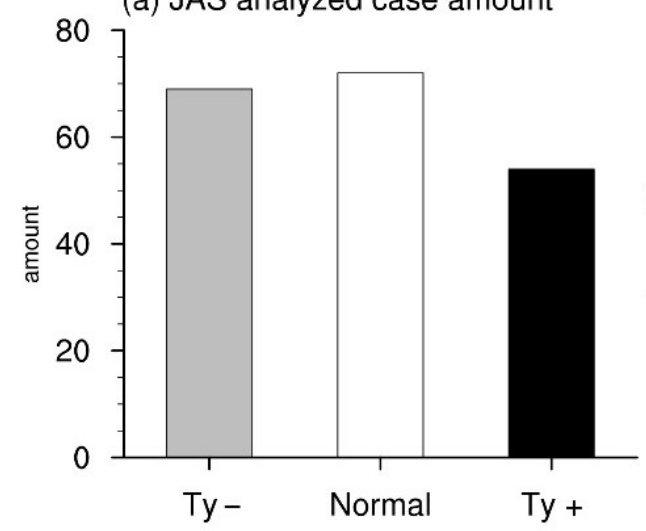

(c) JAS rainfall (avg Taipei, Tainan)

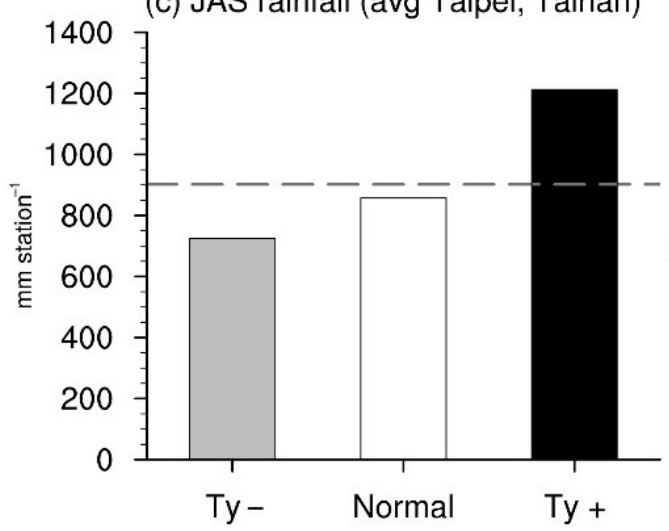

(b) JAS monthly Ty day

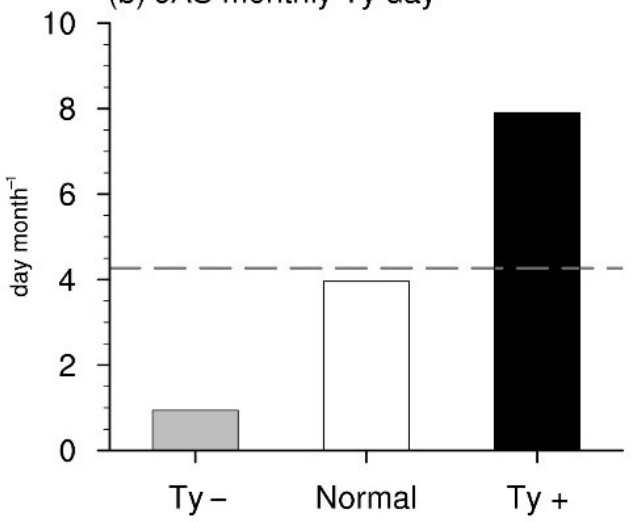

(d) JAS TRI

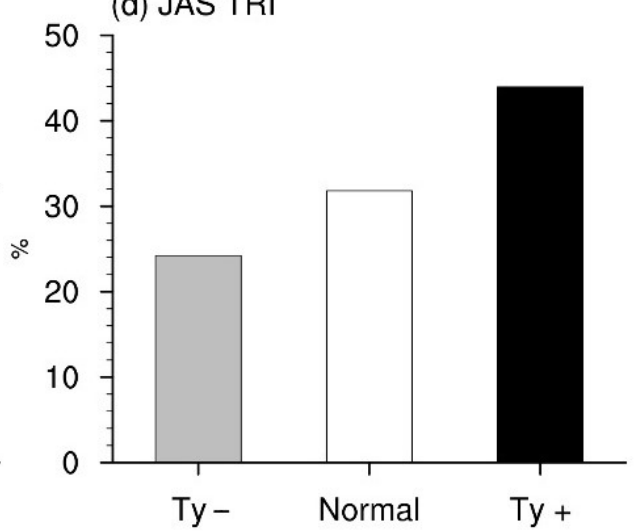

Figure 2. (a) The total amount of the analyzed cases from 1950 to 2014 for the Ty- category (gray bar), the Ty+ category (black bar), and the normal cases (white bar). (b) Same as (a) but for monthly typhoon invasion days (unit: day month ${ }^{-1}$ ). (c) Same as (a) but for total rainfall averaged from the Taipei and Tainan observation stations (unit: $\mathrm{mm} \mathrm{station}^{-1}$ ). (d) Same as (a) but for the proportion of the Taiwan Rainfall Index (TRI) (each category to all; unit: \%). The gray dashed lines in (b) and (c) indicate the climatology calculated over the analyzed period.

According to the statistics, the results within each investigated region reveal somewhat coherent increasing or decreasing rates in both July and August. For the Ty+ category, the amount of typhoons invading Taiwan increases greatly compared to the climatology, with increasing rates of $52.05 \%$ in July and 55.43\% in August; however, in the meantime, the total amount of typhoons generated over the Western North Pacific only slightly increases from the climatology by $7.98 \%$ in July and $10.54 \%$ in August. For the Ty- category, the amount of typhoons invading Taiwan reduces in comparison to the climatological mean, with largely decreasing rates of $52.68 \%$ in July and $76.2 \%$ in August. Different from the weak connection between these two investigated regions in the Ty+ category, considerable reductions in the number of typhoons are also found over the Western North Pacific in the Ty- category, with numbers noticeably lower than the climatology by $20.15 \%$ in July and $18.55 \%$ in August.

The results in September expose disparities in all aspects. For the Ty+ category, the amount of typhoons invading Taiwan shows a massive rise by $67.33 \%$ from the climatology, although the total amount of typhoons over the Western North Pacific is only slightly higher than the climatology by $7.81 \%$. For the Ty- category, the amount of typhoons invading Taiwan decreases greatly by $60.16 \%$ from the climatology; however, over the Western North Pacific, the amount of typhoons is only $2.26 \%$ less than the climatology.

These above results point to a phenomenon as follows: Although the variation in the number of typhoons over the Western North Pacific is a possible factor affecting the number of typhoons invading Taiwan, only the Ty- category in July and August presents a simultaneous decrease in typhoon amount 
for both Taiwan and the Western North Pacific. It means the variation in the number of typhoons generated over the Western North Pacific cannot be directly applied to the extent of the typhoon invasion over Taiwan.

Previously, some studies explored factors that could alter general typhoon motion. Wang et al. (1998) [25] proposed that a wide variety of external and internal dynamical forces and their interaction would lead to the complexity of tropical cyclone motion. Tu et al. (2009) [21] suggested that the abrupt increase of typhoon frequency in the Taiwan region is due to the northward shift of typhoon movements over the Western North Pacific. Wang et al. (2011) [26] showed that the typhoon track changes are linked to global SST warming and the associated changes in large-scale steering flows. With that said, the only way to reasonably and scientifically determine the impacts of a typhoon on Taiwan is to examine the movement of the tropical cyclone. Therefore, in the scope of discussing the change of the typhoon invasion days in Taiwan, this study suggests that one should place emphasis on the linkage between the large-scale environment and the movement of the typhoon.

\subsection{Typhoon Paths and Corresponding Large-Scale Environmental Fields}

A considerable number of typhoons are generated over the Western North Pacific annually, and most of their tracks are traceable. Zhang et al. (2013) $[27,28]$ mentioned that typhoon paths in the Western North Pacific can be roughly classified into two directions: one is going westward to the direction of Taiwan, South China, and the South China Sea; the other is going northward toward Japan and South Korea. Taiwan is at the junction between these two paths and at the turning point of the track for most typhoons over the Western North Pacific-East Asian region [29]. Hence, regardless of the path, the island encounters a high possibility of receiving a typhoon. Composites of the two defined categories, which represent the different extents of typhoon invasion over Taiwan during the typhoon season, are reserved for this section to delve into their corresponding large-scale environmental fields.

\subsubsection{The Ty+ and Ty- Categories}

In order to complete the distribution picture of the typhoon path, the passing frequency from all typhoons in the Ty+ category is shown in Figure 3a. The results clearly indicate that most of the typhoons move toward the northwest after they are generated, and finally pass through Taiwan and the vicinity, especially within the domain for identifying typhoon invasion (domain A, black box in Figure 3a) defined in Section 3.1. In our analysis, most of the areas in the domain A reach extremely high passing frequencies (over 65 times), which clearly reveals a message that Taiwan is extremely vulnerable to the typhoons in these cases. Some typhoons would either travel northward to Japan and South Korea when they approach the east coast of Taiwan or go all the way to the South China Sea through the Bashi Channel (partly through the northern part of Luzon, Philippines); however, the frequencies of these typhoon cases are much lower.

Figure $3 \mathrm{~b}$ shows the corresponding anomalous fields of the SLP and $1000 \mathrm{hPa}$ streamline relative to their climatology for the Ty+ category. Since most of the typhoons in this category will pass through Taiwan and its adjacent areas, the low pressure and cyclonic circulation from the tropical cyclones create an extensive much-lower-than-average pressure area. The area is centered over Taiwan and expands to the surroundings, including South China, the South China Sea, Japan, and South Korea, with anomalous convergent flows above. It indeed suggests that the typhoons frequently pass through Taiwan and the nearby areas in the Ty+ category.

The Ty- category is investigated in the same way, while the results reveal significant differences from the other. Figure $3 \mathrm{c}$ shows the passing frequency from all typhoons in the Ty- category. The results contain information worthy of further discussion. For example, most of the typhoons bypass Taiwan and its nearby areas, and the paths are divided into two main routes: the recurving path to Japan and South Korea, and the westbound path to the South China Sea, characterizing as high passing-frequency (over 60 times) areas on each route, shown by the verification domains B and C mentioned in Section 3.1 (black boxes in Figure 3c). It is worth noting that the westbound path to the South China Sea seems to 
be more south here than those typhoon cases seen in the Ty+ category. The latter tends to pass through the Bashi Channel, yet the former seems to be mainly traveling through Luzon, Philippines.

(a) JAS Ty+ Path frequency

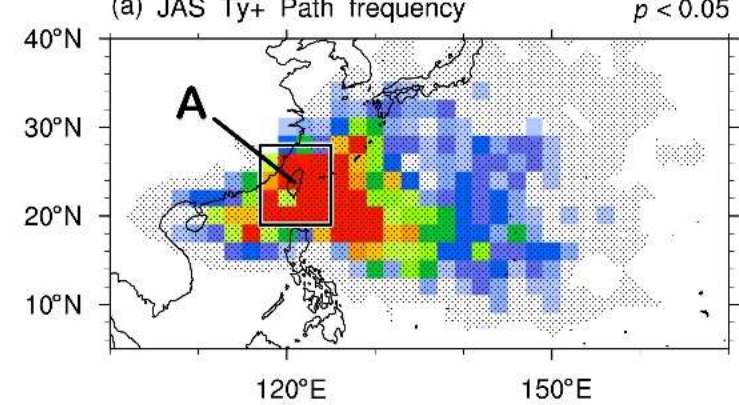

(c) JAS Ty- Path frequency

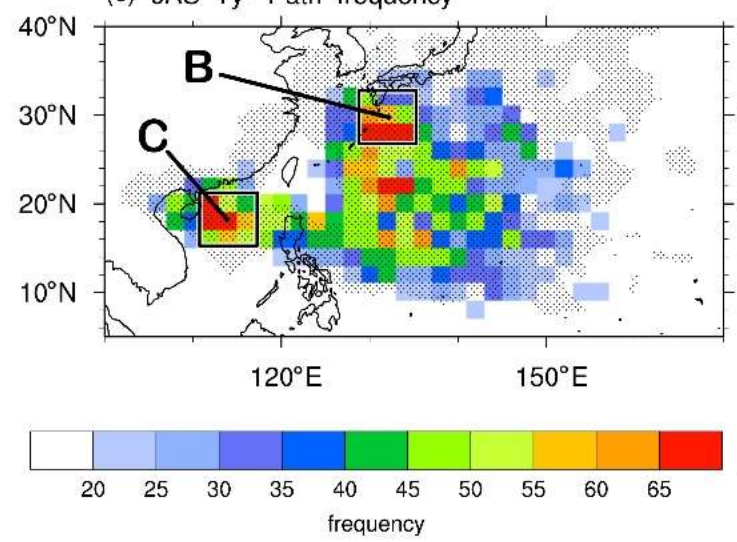

(b) JAS Ty+ SLP, $1000 \mathrm{hPa}$ streamline anomaly

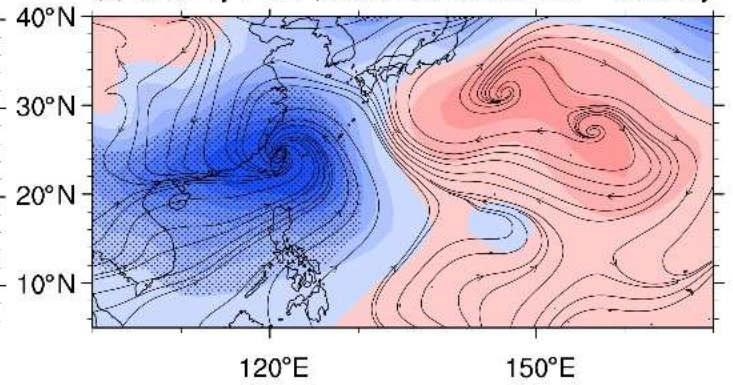

(d) JAS Ty- SLP, $1000 \mathrm{hPa}$ streamline anomaly
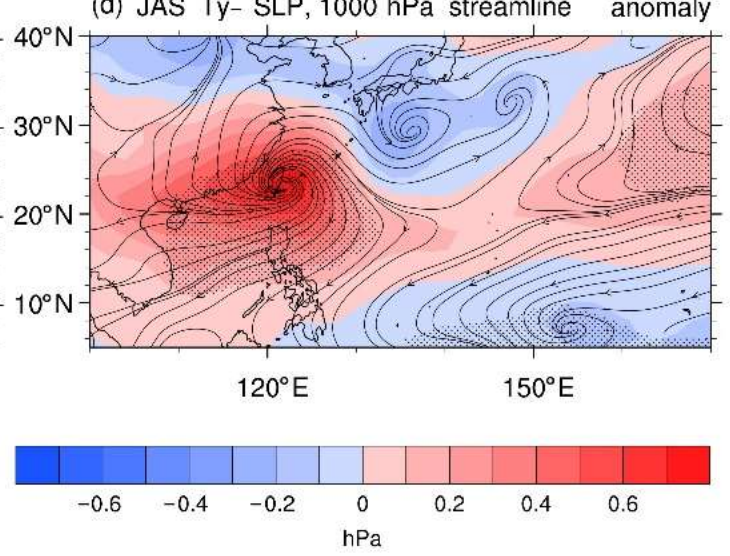

Figure 3. (a) Typhoon passing frequency for the Ty+ category. (b) Sea level pressure (SLP) anomaly (unit: $\mathrm{hPa}$ ) and $1000 \mathrm{hPa}$ streamline anomaly for the Ty+ category. (c) Same as (a) but for the Ty- category.

(d) Same as (b) but for the Ty- category. The black box in (a) shows the typhoon verification domain $\mathrm{A}$, and the black boxes in (c) show the verification domains B and C for typhoon path categorization.

The dots denote areas passing a 95\% confidence level.

The corresponding anomalous SLP and $1000 \mathrm{hPa}$ streamline for the Ty- category are presented in Figure 3d. Opposite to the results from the Ty+ category, the anomalous patterns from the Tycategory show an extensive high-pressure property in a Taiwan-centered area, together with an anticyclonic circulation anomaly above. The phenomenon implies that the area experiences relatively low frequencies of passage by low-pressure systems. It is also possible that the subsidence outflowing from the typhoons would contribute to the stable atmospheric conditions in this area [30] when the tropical cyclones take the bypass. Japan and South Korea, right on one of the main typhoon paths, suffer from frequent typhoon invasions. Hence, an area with anomalous low-pressure and convergence covering these countries is expected. However, another main typhoon moving path, westbound path to the South China Sea, does not show a corresponding negative (or cyclonic) anomalous pattern. In this regard, it is because that region already has relatively low pressures in the climatological field, and thus cyclonic contributions from the typhoons are not prominent.

\subsubsection{The Recurving and Westbound Paths}

Most of the typhoons from the Ty+ category show a relatively simple motion, while there are different types of movement seen in the typhoon cases from the Ty- category. As defined in Section 3.1, the Ty- category is further subcategorized into two different routes: the recurving path and westbound path, which should arise from different large-scale configurations. 
Figure 4 shows the passing frequency of the typhoons from these two paths. For the recurving path (Figure 4a), the verification domain B near Kyushu, Japan reveals fairly high passing frequencies. Another region south of the verification domain B, slightly east of the Ryukyu Islands, also frequently encounters the typhoons passing through. Although that region is outside the verification domain B, it is right on the route of those northbound typhoon cases. Hence, high typhoon passing frequencies are still in line with our expectations.

(a) JAS Ty-Recurving path frequency

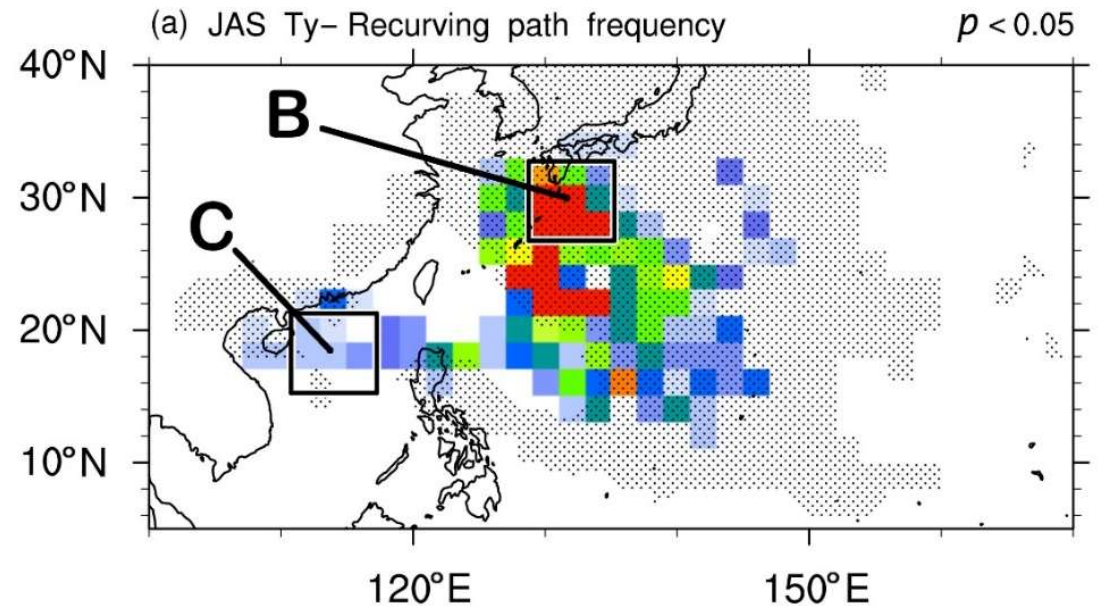

(b) JAS Ty- Westbound path frequency
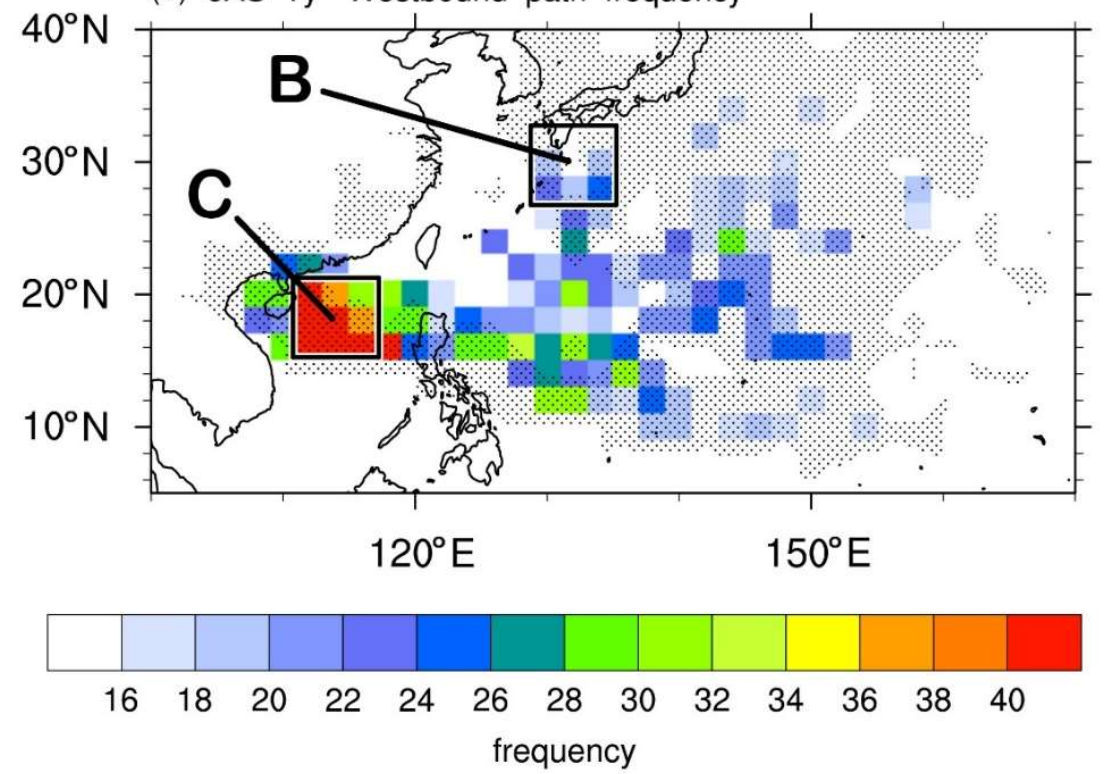

Figure 4. Typhoon passing frequency for the Ty- category is further divided into (a) the recurving path and (b) the westbound path. The black boxes show the verification domains $B$ and $C$ for typhoon path categorization. The dots denote areas passing a 95\% confidence level.

Concerning the westbound path (Figure $4 b$ ), as expected, the verification domain $C$ at the South China Sea has fairly high typhoon passing frequencies. Same as the finding seen in Figure 3c, the typhoons here are more likely to pass through Luzon, Philippines, instead of taking the Bashi Channel as their passage. It seems to imply that in the westbound path scenario, there should be a large-scale force to push the typhoons further moving to the south. Note that there are a few exceptional typhoon tracks that do not comply with their categorized subcategory, such as going westward in the recurving path category. It is because when an analyzed case is individually categorized as the Ty- category, the path with a higher overall typhoon passing frequency within that period would be 
determined for the typhoon path subcategory. In other words, some exceptional typhoon cases moving in other directions or toward the other verification domain with a lower overall passing frequency are not ruled out.

\subsubsection{Corresponding Large-Scale Circulations}

Generally, the path of a typhoon is usually determined by the surrounding large-scale circulation before it makes landfall. Chu et al. (2012), Wang et al. (2011), and Wu et al. (2005) [14,26,31] all suggested that the steering flow is undoubtedly a vital factor in influencing typhoon motion or moving speed. According to the formula defined in Section 3.2, an averaged wind field across $300 \mathrm{hPa}$ to $850 \mathrm{hPa}$ is derived to represent the steering flow in a large-scale background. Thus, corresponding large-scale circulations and related mechanisms that exert influences on the typhoon path can be examined, with three analyzed groups for further study: the Ty+ category, the recurving path of the $\mathrm{Ty}$ - category, and the westbound path of the Ty- category.

The Ty+ category (Figure 5a) shows that the easterly flows dominate the area in the Western North Pacific (east of $150^{\circ} \mathrm{E}$ and south of $24^{\circ} \mathrm{N}$ ). The flows west of $150^{\circ} \mathrm{E}$ gradually turn into the southeasterly and point to Taiwan as well as its surroundings. Regarding the wind speed over this area, the distribution of the strong winds south of $24^{\circ} \mathrm{N}$ extends from the east to the west. Its spatial pattern gradually merges toward the northwest and points to Taiwan at about $130^{\circ} \mathrm{E}$, forming clear steering flows. Since most typhoons over the Western North Pacific are generated around this area, they are likely to be steered toward Taiwan and the surroundings once they are generated. As a result, the island frequently suffers from typhoon hits.

The averaged wind field also discloses other essential messages for further discussion. The large-scale flows gradually turn into the southwesterly at about $24^{\circ} \mathrm{N}$. With the strong westerlies on the north, the flows construct an anticyclonic circulation over the Western North Pacific. The turnaround flows (the southeasterly turning into the southwesterly) on the western side of the anticyclonic circulation lie beside Taiwan, which could make northwestward-moving typhoons too late to recurve when they approach the island. Besides, the anticyclonic circulation contains an almost east-west-shaped weak and calm wind speed zone at about $28^{\circ} \mathrm{N}$. It should be considered as the ridge of the anticyclone [32].

The recurving path from the Ty- category (Figure $5 b$ ) presents a somewhat different pattern. Similar to the Ty+ category, the area east of $150^{\circ} \mathrm{E}$ and south of $24^{\circ} \mathrm{N}$ is dominated by the easterly flows. The flows are also gradually turning into the southeasterly, but the wind direction does not point to Taiwan. Instead, the turnaround flows of the anticyclonic circulation substantially retreat eastward to about $140^{\circ} \mathrm{E}$ and $30^{\circ} \mathrm{N}$, with a relatively strong wind speed region nearby, forming bridge-like flows connecting the westerlies on the north. The connecting flows in that area play a key role in the recurvature. The steering flows first drive typhoons generated from low latitudes to that area. Sequentially, the mentioned bridge-like flows take over the job to guide the typhoons crossing the ridge at about $30^{\circ} \mathrm{N}$. Thus, the typhoons move toward Japan and then are steered away by the westerlies, completing the process of the recurvature.

In addition, there is another path of the airflow over the Bashi Channel and Luzon, Philippines, heading to the South China Sea and Hainan. From the wind speed field, the wind speed across the Bashi Channel and Luzon, Philippines, is relatively similar to the mentioned bridge-like flows south of Japan, although its spatial pattern is much more extensive than the other one. However, the re-enhancement of the wind speed over the South China Sea is not that prominent compared to the much stronger westerlies above Japan (or north of the recurving path). It consequently leads to the fact that most typhoons tend to be towed by the turnaround flows south of Japan and the strong westerlies toward the north, rather than going westward when they are guided to areas around $140^{\circ} \mathrm{E}$. Certainly, there are some exceptional typhoons cases that would instead follow the relatively weak flows south of Taiwan toward the South China Sea. As the results seen in Figure 4a, few typhoons take the westbound path through Luzon, Philippines, to the South China Sea in the recurving path scenario. 
(a) JAS Ty+300-850 hPa flow

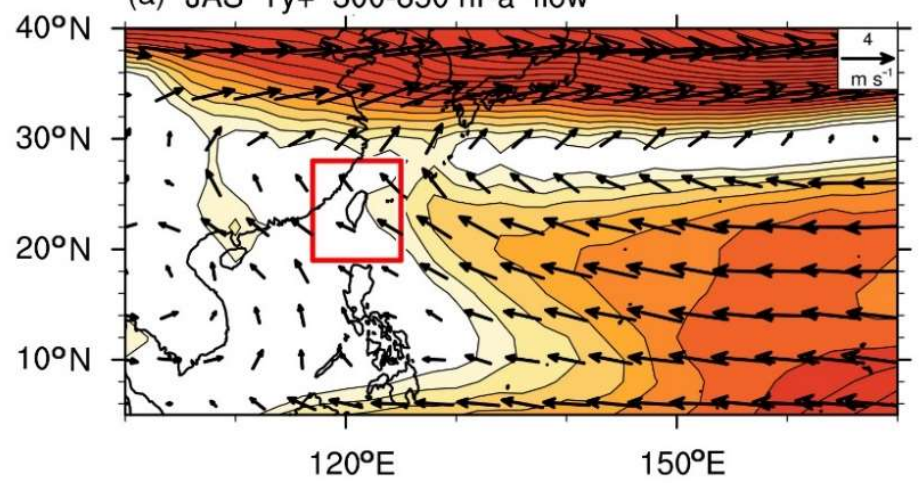

(b) JAS Ty- Recurving path $300-850 \mathrm{hPa}$ flow

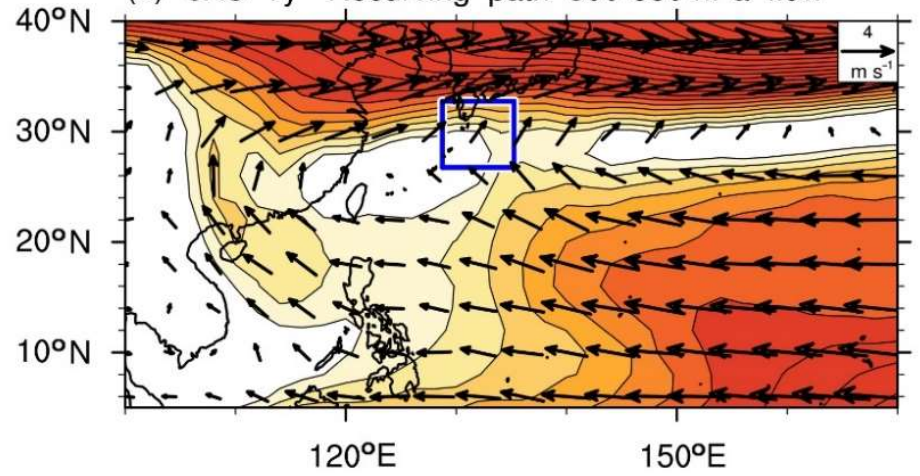

(c) JAS Ty- Westbound path $300-850 \mathrm{hPa}$ flow

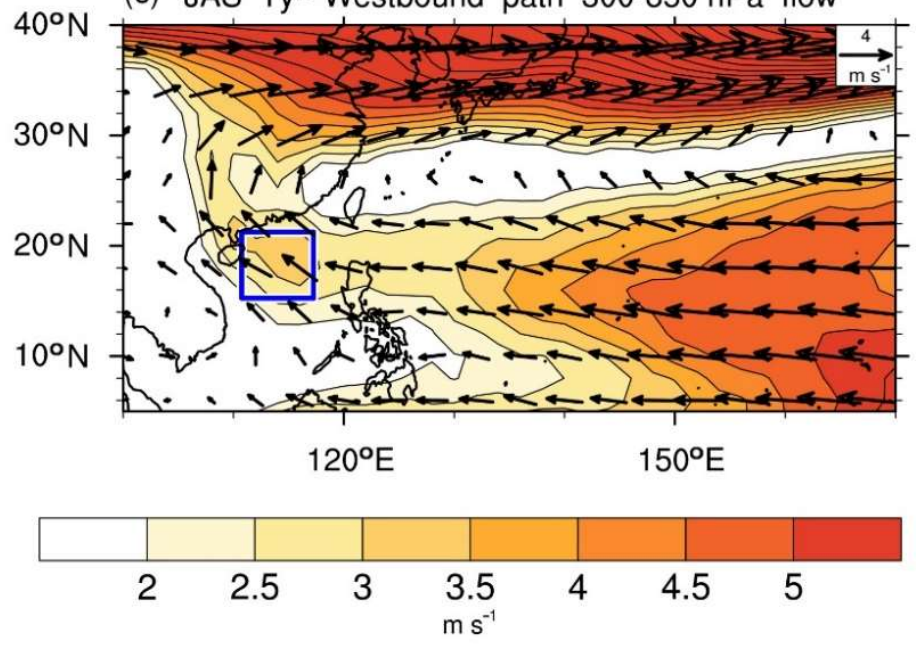

Figure 5. The steering flow averaged from $300 \mathrm{hPa}$ to $850 \mathrm{hPa}$ shown by vectors and wind speed (unit: $\mathrm{m} \mathrm{s}^{-1}$ ) for (a) the Ty+ category, (b) the recurving path of the Ty- category, and (c) the westbound path of the Ty- category. The red box in (a) shows the typhoon verification domain A, and the blue boxes in (b) and (c) show the verification domains B and C for typhoon path categorization.

Regarding the westbound path from the Ty- category (Figure 5c), the area south of $24^{\circ} \mathrm{N}$ is still dominated by the easterly flows. However, the changing from the easterly to the southeasterly is subtle; instead, the main flows go westward through the Bashi Channel and Luzon, Philippines. After arriving over the South China Sea and South China, the flows gradually turn into the southeasterly and even the southerly, which indicates the position of the western edge of the anticyclonic circulation.

The wind speed field shows a similar spatial pattern. The strong wind zone south of $28^{\circ} \mathrm{N}$ gradually merges toward areas on the west at $18^{\circ} \mathrm{N}$, including the Bashi Channel and Luzon, Philippines, while the wind speed here is higher than that in the recurving path scenario. The conspicuous bridge-like 
flows south of Japan seen in the recurving path scenario disappear. Besides, a weak and calm wind speed zone, which is regarded as the ridge, now extends all the way to Taiwan, blocking out most typhoons from passing by like a barrier and leading them to the South China Sea on the west. It also could be a reason why the typhoons are forced to move through Luzon, Philippines, instead of the Bashi Channel on the north, and it more or less creates a hard time for those typhoons to affect southern Taiwan. Despite the ridge across the ocean, there are some southerly flows at around $140^{\circ} \mathrm{E}$ and $28^{\circ} \mathrm{N}$, which should explain why there are still few recurving typhoons in the westbound path scenario.

\subsubsection{Typhoon Paths and the Position of the Pacific Subtropical High}

In the analyses of the steering flow, the anticyclonic circulation over the Western North Pacific is certainly not a negligible feature, and obviously, most typhoons would follow the flows around the circulation of the anticyclone. The trade winds, south of the subtropical high, is responsible for the general westward motion of typhoons, and the flows on the western edge of this large-scale anticyclone take over the job for the poleward motion [33]. Given that the flows are mainly controlled by the subtropical high, this study analyzes the $500 \mathrm{hPa}$ geopotential height to represent the location of the Pacific subtropical high and investigates its relationship with different typhoon routes. In order to quickly determine the margin of the subtropical high, Figure 6 highlights the $5880 \mathrm{~m}$ contour and $5870 \mathrm{~m}$ contour as a thick solid line and a thick dashed line, respectively.

Figure 6a shows the $500 \mathrm{hPa}$ geopotential height field for the Ty+ category. The westmost side of the $5880 \mathrm{~m}$ contour is located south of Honshu, Japan, at about $130^{\circ} \mathrm{E}$ and $28^{\circ} \mathrm{N}$. The western edge of the $5870 \mathrm{~m}$ contour lies further west, about southwest of Kyushu, Japan, and northwest of the Ryukyu Islands. According to the results from the previous analyses of the steering flow, the anticyclonic circulation is roughly aligned with the $5870 \mathrm{~m}$ contour, with the ridge at approximately $28^{\circ} \mathrm{N}$, shown before as a weak and calm wind speed zone. Therefore, when the western margin of the Pacific subtropical high lies between Kyushu, Japan, and Taiwan, the accompanying steering flow would lead typhoons from the low latitudes toward Taiwan and its adjacent areas, leading to an increase in the typhoon invasion days.

The Pacific subtropical high considerably retreats eastward in the recurving path of the Tycategory, as shown by the $5880 \mathrm{~m}$ and $5870 \mathrm{~m}$ contours in Figure $6 \mathrm{~b}$. The western edge of the $5870 \mathrm{~m}$ contour shrinks eastward from the region between Taiwan and Kyushu, Japan, to the place south of Kyushu, Japan. Similar to the results from the Ty+ category, the position of the $5870 \mathrm{~m}$ contour coincides with the anticyclonic circulation seen in the analyses of the steering flow. Therefore, when the Pacific subtropical high retreats eastward and its western edge is located south of Kyushu, Japan, typhoons are likely to be transferred northward by the steering flow toward Japan without affecting Taiwan.

Regarding the westbound path of the Ty- category (Figure 6c), although the position of the $5880 \mathrm{~m}$ contour shrinks slightly more to the east in comparison to what it behaves in the recurving path scenario, the $5870 \mathrm{~m}$ contour widely extends further to the west and even covers Taiwan. The pattern of the ridge crossing over Taiwan is the same as that from the analyses of the steering flow. The stable atmospheric environment under the ridge acts as a barrier to hinder typhoons from passing by Taiwan. Once again, as seen in the previous findings, the anticyclonic circulation here is also roughly consistent with the $5870 \mathrm{~m}$ contour. As a result, when the property of the Pacific subtropical high dominates areas over Taiwan, typhoons are unlikely to invade the island nor to recurve. Instead, they would be led by the steering flow toward the west, heading westward to the South China Sea through Luzon, Philippines. Under this circumstance, Taiwan is more likely to avoid the threat from the typhoon. 
(a) JAS Ty+ $500 \mathrm{hPa}$ HGT

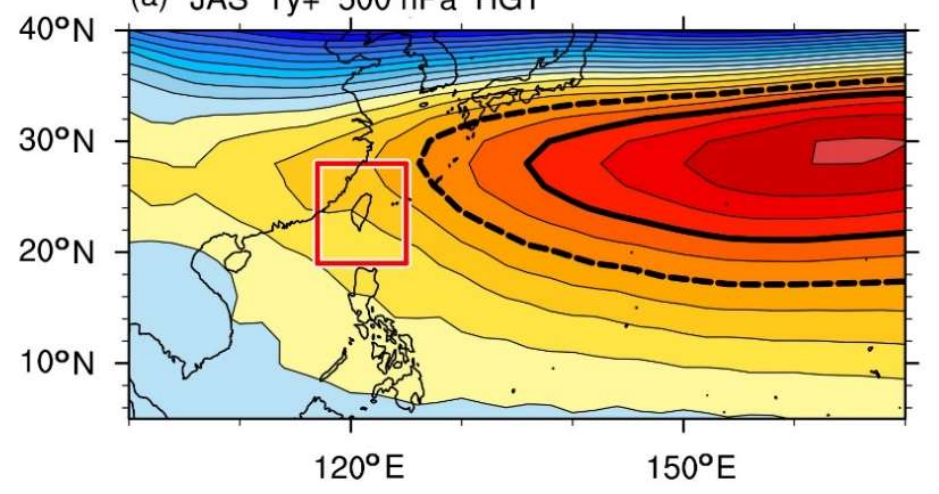

(b) JAS Ty-Recurving path $500 \mathrm{hPa}$ HGT

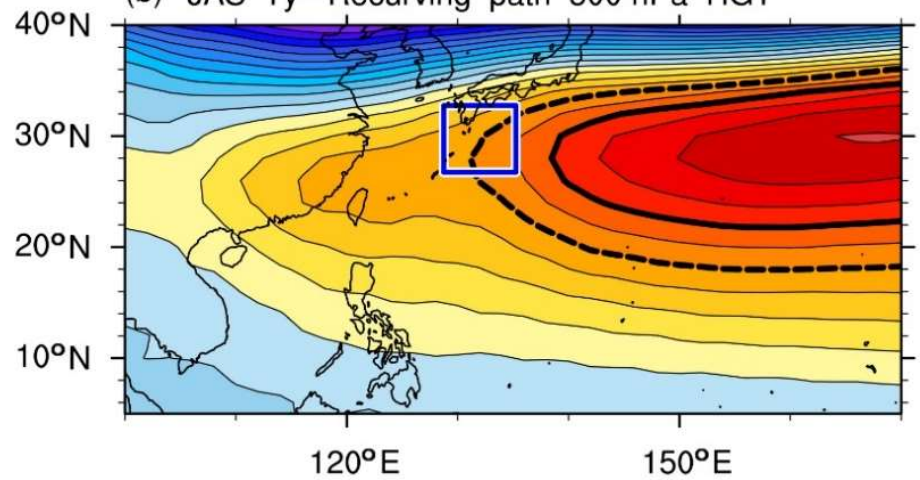

(c) JAS Ty- Westbound path $500 \mathrm{hPa}$ HGT

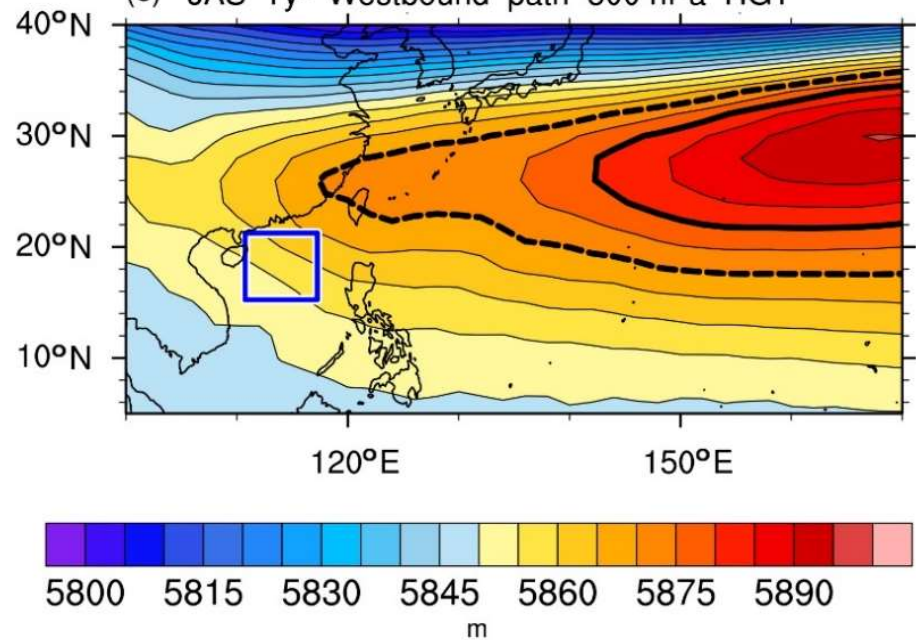

Figure 6. Geopotential height at $500 \mathrm{hPa}$ (unit: $\mathrm{m}$ ) for (a) the Ty+ category, (b) the recurving path of the Ty- category, and (c) the westbound path of the Ty- category. The thick solid and dashed contours represent the $5880 \mathrm{~m}$ and $5870 \mathrm{~m}$ geopotential heights, respectively. The red box in (a) shows the typhoon verification domain $\mathrm{A}$, and the blue boxes in (b) and (c) show the verification domains B and C for typhoon path categorization.

\section{Discussion and Conclusions}

\subsection{Discussion}

There are certainly other factors that can influence the movement and intensity of typhoons over the Western North Pacific. The Madden-Julian Oscillation (MJO) [34-36] is an eastward-moving intra-seasonal phenomenon that has been well discussed in terms of its broad impacts on precipitation, surface temperature, tropical cyclones, and monsoons [37-39]. The northward or northwestward 
propagating mode in the Northern Hemisphere during the boreal summer within the intra-seasonal time scale [40-42], specifically named the boreal summer intra-seasonal oscillation (BSISO), has interactions with typhoon activities over the Western North Pacific [43-45]. Our previous study, Hung et al. (2016) [46], showed that the typhoon frequency patterns associated with heavy rainfall in Taiwan are closely related to the 10 to 30-day BSISO2 phases during the typhoon season. When the major BSISO2 convection moves northwestward from the Philippine Sea to Taiwan and adjacent areas, during phases 3 and 4 , an anomalous low-level cyclonic flow and increased typhoon frequency directly contribute to larger rainfall in Taiwan.

Although the MJO has shown to be one of the prominent factors impacting on typhoon frequency in the Taiwan region, its intra-seasonal time scale signal, particularly the 10 to 30-day MJO phases, does not match the scope of the seasonal time scale examined in this study. The three-month investigated spell from July to August in this research was chosen to best reflect the typhoon-associated large-scale backgrounds during the most active period in the typhoon season for Taiwan. Therefore, the direct influences exerted by the MJO may not be crucial here.

The El Niño Southern Oscillation (ENSO) is another major factor that can extensively alter atmospheric systems over the Western North Pacific [47,48]. Kubota (2012) [49] indicated ENSO can modulate typhoon activity, including typhoon genesis location, landfall numbers, intensity, life span, and rainfall, mainly through the relocation of a monsoon trough with the eastward shift of the Walker circulation. Apart from the conventional Eastern Pacific warming El Niño events, a noncanonical El Niño type (also known as central Pacific El Niño or El Niño Modoki), which is characterized by equatorial central warming, has been recently observed [50,51].

The different types of El Niño, SST warming patterns, and vertical motions all have their mechanisms to change the behavior of atmospheric systems associated with typhoon tracks, such as the location and intensity of the subtropical high, the strength of the low-level vorticity, the monsoon trough, and large-scale circulations [21,52,53], which adds more complexity to the entire story. Therefore, to build a linkage between the above factors and our results remains the quest of further studies in the future to clarify the entire physical process. Under this consideration, the current goal of this study mainly focuses on investigating the steering flow and associated typhoon tracks from a climatological perspective.

\subsection{Concluding Remarks}

Typhoons generated over the Western North Pacific always make a profound impact on East and Southeast Asian countries. They become more active in the boreal summer and fall, while any deviation of their movement can bring a different result to Taiwan owing to the small geographical area of the island. This study counts the amount of the typhoon invasion days in Taiwan for each investigated month from July to September over the period of 1950 to 2014, to establish numerous analyzed cases. Those cases are classified into the Ty+ and $\mathrm{Ty}-$ categories by the statistical thresholds to represent the different extents of typhoon impacts on Taiwan. After investigating the corresponding typhoon paths from each category, our work demonstrates that there are two types of typhoon movements with completely different routes in the Ty- category. Therefore, the Ty- category is further subdivided into two additional subcategories. Finally, three groups for the analysis are established, namely "the Ty+ category", "the recurving path of the Ty- category", and "the westbound path of the Ty- category".

Through examining composites for each group, the large-scale environmental fields and corresponding typhoon motions can be clearly clarified, and the final results are presented in a schematic plot, as shown in Figure 7. The $5880 \mathrm{~m}$ and $5870 \mathrm{~m}$ contours of the $500 \mathrm{hPa}$ geopotential height field represent the margin of the Pacific subtropical high. The variation in their positions is used to explain the mechanisms causing different typhoon motions. 


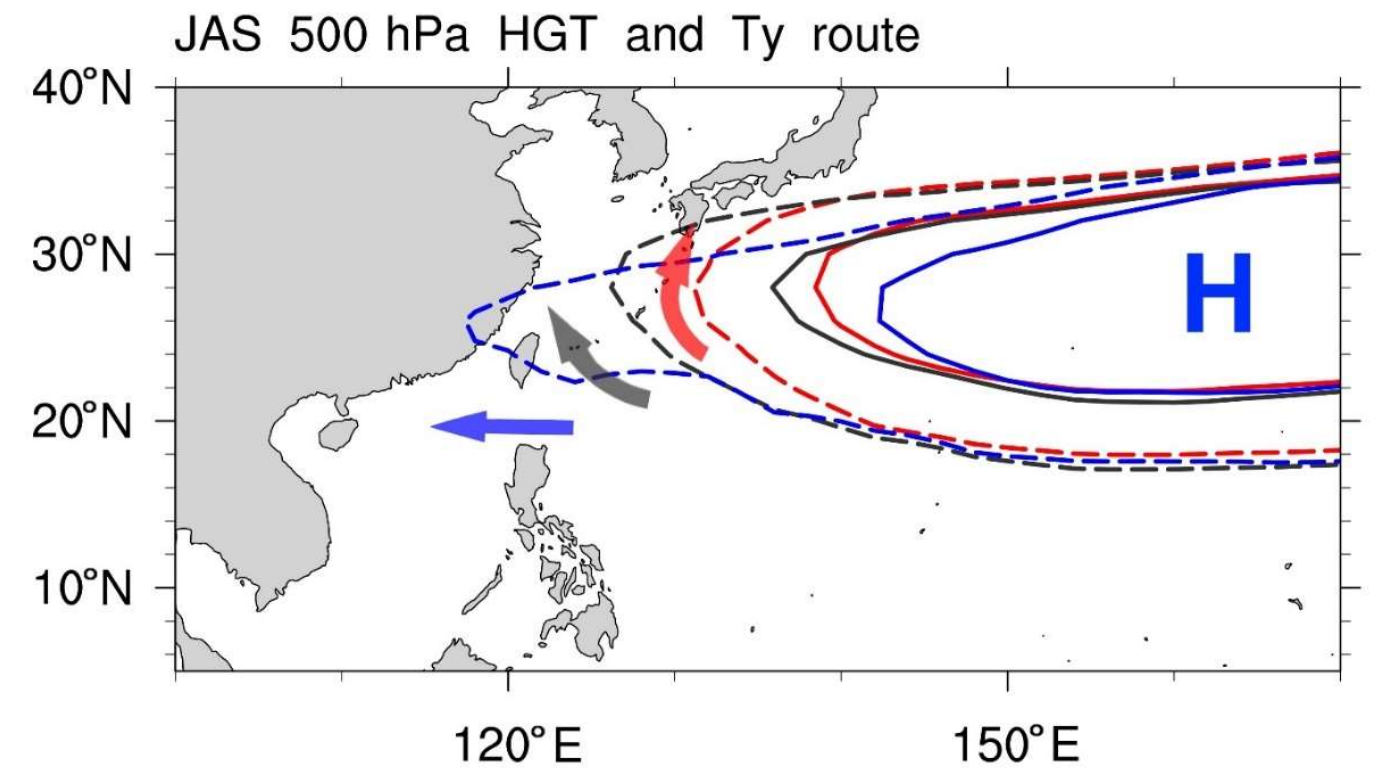

Figure 7. The schematic diagram to illustrate the position of the margin of the Pacific subtropical high and corresponding typhoon route. Dark gray for the Ty+ category, red for the recurving path of the Ty- category, and blue for the westbound path of the Ty- category. The solid and dashed contours represent the $5880 \mathrm{~m}$ and $5870 \mathrm{~m}$ geopotential heights, respectively. The arrows indicate different typhoon routes.

When the western edge of the Pacific subtropical high is located between Taiwan and Kyushu, Japan, the steering flow controlled by the margin of the Pacific subtropical high tends to steer typhoons generated at low latitudes directly toward Taiwan on the northwest. Alternatively, the flow leads the typhoons to make a late recurvature toward Japan and South Korea while the tropical cyclones approach the east coast of Taiwan. In either way, Taiwan is likely to suffer from typhoon hits.

When the Pacific subtropical high considerably shrinks to the east, and its western edge lies southeast of Japan, typhoons generated at low latitudes are still easily guided to their northwest. However, the steering flow accompanying the retreating subtropical high would turn around at the western margin of the high and thus takes the typhoons to recurve before reaching the Ryukyu Islands. Under this circumstance, only few typhoons have a chance to impact Taiwan.

In contrast, when the Pacific subtropical high widely extends the property to its west including Taiwan, the ridge is like a barrier to block out typhoons from passing through. In this scenario, Taiwan is apparently under a stable and hot summer weather condition. The westward-extending subtropical high controls the easterly steering flow along its southern margin to flow through the Bashi Channel and Luzon, Philippines. When arriving at the South China Sea, the steering flow starts to turn clockwise over Hainan or even South China. In this scenario, the typhoons are likely to be driven by the flow, following the same route toward the west. In addition, most of the typhoons here tend to move through Luzon, Philippines, rather than taking the Bashi Channel, which certainly further reduces the threat to Taiwan.

Compared with previous typhoon-related studies, the features of this work are highlighted as follows: First, rather than directly studying each individual typhoon, our work categorizes multiple analyzed cases from a climatological perspective to understand the linkage between the different typhoon paths and their corresponding large-scale environmental fields. Secondly, in the analyses for the Ty- category, different typhoon paths are further classified to avoid compound messages from different corresponding large-scale environmental configurations. All these features demonstrate different perspectives of analysis to enrich the framework of typhoon-related topics. Therefore, our work can help to indicate noteworthy messages that have not been properly discussed through 
conventional study methods, and the relevant understandings from this study should provide valuable support to typhoon forecasting in the future.

Author Contributions: Conceptualization, C.-W.H.; formal analysis, C.-W.H., T.-Y.L. and M.-F.S.; writing-original draft, M.-F.S.; writing-review and editing, C.-W.H. All authors have read and agreed to the published version of the manuscript.

Funding: This work was supported under the funding from the Ministry of Science and Technology, Taiwan (MOST 108-2111-M-003-001).

Acknowledgments: The authors thank two reviewers for their useful comments on the manuscript. This work was supported under the funding from the Ministry of Science and Technology, Taiwan (MOST 108-2111-M-003-001).

Conflicts of Interest: The authors declare no conflict of interest.

\section{References}

1. Yumoto, M.; Matsuura, T. Interdecadal variability of tropical cyclone activity in the western North Pacific. J. Meteorol. Soc. Jpn. 2001, 79, 23-35. [CrossRef]

2. Chien, F.-C.; Kuo, H.-C. On the extreme rainfall of Typhoon Morakot (2009). J. Geophys. Res. 2011, 116, D05104. [CrossRef]

3. Huang, C.-Y.; Wu, I.-H.; Feng, L. A numerical investigation of the convective systems in the vicinity of southern Taiwan associated with Typhoon Fanapi (2010): Formation mechanism of double rainfall peaks. J. Geophys. Res. Atmos. 2016, 121, 12647-12676. [CrossRef]

4. Su, S.-H.; Kuo, H.-C.; Hsu, L.-H.; Yang, Y.-T. Temporal and spatial characteristics of typhoon extreme rainfall in Taiwan. J. Meteorol. Soc. Jpn. 2012, 90, 721-736. [CrossRef]

5. Kubota, H.; Wang, B. How much do tropical cyclones affect seasonal and interannual rainfall variability over the Western North Pacific? J. Clim. 2009, 22, 5495-5510. [CrossRef]

6. Hung, C.W.; Hsu, H.H. Contribution of typhoons to the rainfall in Taiwan. In Proceedings of the 14th International Conference on Geography in Taiwan, NTNU, Taipei, Taiwan, 22-23 May 2010.

7. Chen, J.-M.; Li, T.; Shih, C.-F. Tropical cyclone and monsoon-induced rainfall variability in Taiwan. J. Clim. 2010, 23, 4107-4120. [CrossRef]

8. Chen, J.-M.; Chen, H.-S. Interdecadal variability of summer rainfall in Taiwan associated with tropical cyclones and monsoon. J. Clim. 2011, 24, 5786-5798. [CrossRef]

9. Chen, J.-M.; Fan, H.-L. Interannual Variability of the South China Sea Summer Rainfall and Typhoon Invading Taiwan. Atmos. Sci. 2003, 31, 221-238. (In Chinese)

10. Tu, J.-Y.; Chen, J.-M. Large-scale indices for assessing typhoon activity around Taiwan. Int. J. Climatol. 2019, 39, 921-933. [CrossRef]

11. Matsuno, T. Quasi-geostrophic motions in the equatorial area. J. Meteorol. Soc. Jpn. 1966, 44, 25-43. [CrossRef]

12. Gill, A.E. Some simple solutions for heat-induced tropical circulation. Q. J. R. Meteorol. Soc. 1980, 106, 447-462. [CrossRef]

13. Nitta, T. Convective activities in the tropical western Pacific and their impact on the Northern Hemisphere summer circulation. J. Meteorol. Soc. Jpn. 1987, 65, 373-390. [CrossRef]

14. Chu, P.-S.; Kim, J.-H.; Chen, Y.-R. Have steering flows over the western North Pacific and the South China Sea changed over the last 50 years? Geophys. Res. Lett. 2012, 39, L10704. [CrossRef]

15. Tu, J.-Y.; Chou, C. Changes in precipitation frequency and intensity in the vicinity in Taiwan: Typhoon vs. non-typhoon events. Environ. Res. Lett. 2013, 8, 014023. [CrossRef]

16. Chang, C.-P.; Yang, Y.-T.; Kuo, H.-C. Large increasing trend of tropical cyclone rainfall in Taiwan and the role of terrain. J. Clim. 2013, 26, 4138-4147. [CrossRef]

17. Huang, Y.-H.; Wu, C.-C.; Wang, Y. The Influence of Island Topography on Typhoon Track Deflection. Mon. Wea. Rev. 2011, 139, 1708-1727. [CrossRef]

18. Yeh, T.C.; Hsiao, L.F.; Chen, D.S.; Huang, K.N. A study on terrain-induced tropical cyclone looping in East Taiwan: Case study of Typhoon Haitang in 2005. Nat. Hazards 2012, 63, 1497-1514. [CrossRef]

19. Hung, C.W. The Construction of TCCIP Taiwan Rainfall Index (TRI) and its Applications. J. Geogr. Sci. 2012, 67, 73-96. (In Chinese)

20. Physical Sciences Laboratory. Available online: https://www.esrl.noaa.gov/psd/ (accessed on 2 February 2018). 
21. Tu, J.-Y.; Chou, C.; Chu, P.-S. The abrupt shift of typhoon activity in the vicinity of Taiwan and its association with western North Pacific-East Asian climate change. J. Clim. 2009, 22, 3617-3628. [CrossRef]

22. Kimberlain, T.B.; Breman, M.J. Chapter 3: Tropical cyclone motion. In Global Guide to Tropical Cyclone Forecasting, 2nd ed.; Guard, C.C., Ed.; WMO: Geneva, Switzerland, 2017; pp. 63-125. ISBN 978-92-63-11194-4.

23. Holland, G.J. Chapter 3: Tropical cyclone motion. In Global Guide to Tropical Cyclone Forecasting, 1st ed.; Holland, G.J., Ed.; WMO: Geneva, Switzerland, 1993; pp. 3.1-3.48. ISBN 978-92-63-11194-4.

24. Chen, Y.S.; Kuo, Y.S.; Lai, W.C.; Tsai, Y.J.; Lee, S.P.; Chen, K.T.; Shieh, C.L. Reflection of typhoon morakot-The challenge of compound disaster simulation. J. Mt. Sci. 2011, 8, 571-581. [CrossRef]

25. Wang, B.; Russell, E.; Wang, Y.; Wu, L. Dynamics in tropical cyclone motion. Chin. J. Atmos. Sci. 1998, 22, 416-434.

26. Wang, R.; Wu, L.; Wang, C. Typhoon track changes associated with global warming. J. Clim. 2011, 24, 3748-3752. [CrossRef]

27. Zhang, W.; Leung, Y.; Chan, J.C. The analysis of tropical cyclone tracks in the western North Pacific through data mining. Part I: Tropical cyclone recurvature. J. Appl. Meteorol. Climatol. 2013, 52, 1394-1416. [CrossRef]

28. Zhang, W.; Leung, Y.; Chan, J.C. The analysis of tropical cyclone tracks in the western North Pacific through data mining. Part II: Tropical cyclone landfall. J. Appl. Meteorol. Climatol. 2013, 52, 1417-1432. [CrossRef]

29. Camargo, S.J.; Robertson, A.W.; Gaffney, S.J.; Smyth, P.; Ghil, M. Cluster analysis of typhoon tracks. Part I: General properties. J. Clim. 2007, 20, 3635-3653. [CrossRef]

30. Edwards, J. Tropical Cyclone Formation. Available online: https://www.hurricanezone.net/articles/ tropicalcycloneformation.html (accessed on 1 May 2020).

31. Wu, L.; Wang, B.; Geng, S. Growing typhoon influence on east Asia. Geophys. Res. Lett. 2005, 32, L18703. [CrossRef]

32. Horse Latitudes. Available online: http://www.worldwidewords.org/qa/qa-hor3.htm (accessed on 1 May 2020).

33. Zehnder, J.A. Tropical cyclone. Available online: https://www.britannica.com/science/tropical-cyclone/Lifeof-a-cyclone (accessed on 1 May 2020).

34. Madden, R.A.; Julian, P.R. Detection of a 40-50 day oscillation in the zonal wind in the tropical Pacific. J. Atmos. Sci. 1971, 28, 702-708. [CrossRef]

35. Madden, R.A.; Julian, P.R. Description of global-scale circulation cells in the tropics with a 40-50 day period. J. Atmos. Sci. 1972, 29, 1109-1123. [CrossRef]

36. Madden, R.A.; Julian, P.R. Observations of the 40-50-day tropical oscillation-A review. Mon. Weather Rev. 1994, 122, 814-837. [CrossRef]

37. Jones, C.; Waliser, D.E.; Lau, K.M.; Stern, W. Global occurrences of extreme precipitation and the Madden-Julian oscillation: Observations and predictability. J. Clim. 2004, 17, 4575-4589. [CrossRef]

38. Zhang, C. Madden-Julian Oscillation. Rev. Geophys. 2005, 43, RG2003. [CrossRef]

39. Donald, A.; Meinke, H.; Power, B.; Maia, A.D.; Wheeler, M.C.; White, N.; Stone, R.C.; Ribbe, J. Near-global impact of the Madden-Julian Oscillation on rainfall. Geophys. Res. Lett. 2006, 33, L09704. [CrossRef]

40. Yasunari, T. Cloudiness fluctuations associated with the northern hemisphere summer monsoon. J. Meteorol. Soc. Jpn. 1979, 57, 227-242. [CrossRef]

41. Yasunari, T. A quasi-stationary appearance of 30 to 40 day period in the cloudiness fluctuations during the summer monsoon over India. J. Meteorol. Soc. Jpn. 1980, 58, 225-229. [CrossRef]

42. Yasunari, T. Structure of an Indian summer monsoon system with around 40-day period. J. Meteorol. Soc. Jpn. 1981, 59, 336-354. [CrossRef]

43. Kim, J.H.; Ho, C.H.; Kim, H.S.; Sui, C.H.; Park, S.K. Systematic variation of summertime tropical cyclone activity in the western North Pacific in relation to the Madden-Julian oscillation. J. Clim. 2008, 21, 1171-1191. [CrossRef]

44. Li, R.C.; Zhou, W. Modulation of western North Pacific tropical cyclone activity by the ISO. Part I: Genesis and intensity. J. Clim. 2013, 26, 2904-2918. [CrossRef]

45. Chen, G.; Chou, C. Joint Contribution of multiple equatorial waves to tropical cyclogenesis over the western North Pacific. Mon. Weather Rev. 2014, 142, 79-93. [CrossRef]

46. Hung, C.W.; Lin, H.J.; Kao, P.K.; Shih, M.F.; Fong, W.Y. Boreal Summer Intraseasonal Oscillation Impact on Western North Pacific Typhoons and Rainfall in Taiwan. Terr. Atmos. Ocean. Sci. 2016, 27, 893-906. [CrossRef]

47. Elsner, J.B.; Liu, K.B. Examining the ENSO-typhoon hypothesis. Clim. Res. 2003, 25, 43-54. [CrossRef] 
48. Camargo, S.J.; Sobel, A.H. Western North Pacific Tropical Cyclone Intensity and ENSO. J. Clim. 2005, 18, 2996-3006. [CrossRef]

49. Kubota, H. Variability of typhoon tracks and genesis over the Western North Pacific. In Cyclones: Formation, Triggers and Control; Oouchi, K., Fudeyasu, H., Eds.; Nova Science Publishers: New York, NY, USA, 2012; pp. 95-114.

50. Ashok, K.; Behera, S.K.; Rao, S.A.; Weng, H.; Yamagata, T. El Niño Modoki and its possible teleconnection. J. Geophys. Res. 2007, 112, C11007. [CrossRef]

51. Lee, T.; McPhaden, M.J. Increasing intensity of El Niño in the central-equatorial Pacific. Geophys. Res. Lett. 2010, 37, L14603. [CrossRef]

52. Zhang, W.; Graf, H.; Leung, Y.; Herzog, M. Different El Niño Types and Tropical Cyclone Landfall in East Asia. J. Clim. 2012, 25, 6510-6523. [CrossRef]

53. Sui, C.-H.; Chung, P.-H.; Li, T. Interannual and interdecadal variability of the summertime western North Pacific subtropical high. Geophys. Res. Lett. 2007, 34, L11701. [CrossRef]

(C) 2020 by the authors. Licensee MDPI, Basel, Switzerland. This article is an open access article distributed under the terms and conditions of the Creative Commons Attribution (CC BY) license (http://creativecommons.org/licenses/by/4.0/). 